\title{
Serenity-Uses in the Care of Chronically Ill Older Patients: A Concept Clarification*
}

\author{
Margaretha Norell Pejner \\ School of Social and Health Sciences, Halmstad University, Halmstad, Sweden \\ Email: margaretha.pejner@hh.se
}

Received 9 December 2014; revised 29 December 2014; accepted 6 January 2015

Copyright (C) 2015 by author and Scientific Research Publishing Inc.

This work is licensed under the Creative Commons Attribution International License (CC BY). http://creativecommons.org/licenses/by/4.0/

(c) (i) Open Access

\section{Abstract}

Serenity is an emotional experience that contributes to the acceptance of a situation. One phenomenon in the care of chronically ill older patients and patients in end of life care is that too much focus is placed on the patient's disease. This can contribute to anxiety, sadness or sense of isolation. For older people that are chronically ill or in care at the end of life, it is important that the registered nurse can help them to find serenity. Further knowledge is needed about how the concept of serenity is used in relation to the care of older chronically ill patients. Aim: The purpose of this concept analysis was to clarify how serenity is used in nursing and in relation to the care of chronically ill older patients. Method: The study follows Rodgers' evolutionary method of concept analysis. Findings: Serenity is a state of physical, mental, emotional and spiritual balance when life conditions can be managed or accepted. Through the experience of serenity the chronically ill older patient is able to find or develop the self in order to continue with dignity. The concept is most used at the lowest described levels of the self, including a perception of personal safety. The highest level involves a sense of wholeness and awareness. Conclusion: The concept of serenity is used in relation to chronically ill older patients as a condition where the patient finds balance and thus can manage or accept their situation. Chronically ill older patients will not recover. For that reason it needed a better understanding about what factors to experience serenity are needed. Further research is also needed to examine how registered nurses can support older chronically patients in finding serenity with the help of nursing interventions.

\section{Keywords}

Chronically Ill, Concept Analysis, Nursing, Older Patients, Serenity

\footnotetext{
*Serenity—a concept clarification.
} 


\section{Introduction}

Concept development is a significant method for obtaining theoretical knowledge in caring science [1]. Concepts are seen as the basis of a theory and provide the tools required in practice and in research [2]. By approaching a concept based on its intended use, context or era, new dimensions can be developed [2].

The concept of serenity is described as an emotional experience characterized by a state of awareness which contributes to the acceptance of a situation [3]. Being serene is also important because it is in the serene state can a person see objective on their own situation and thus get the ability to act in order to change their situation [4]. Since the 1980s, the concept of serenity has been present in nursing [5] but not extensively applied as a concept into nursing. The definition of the concept within nursing is based on Gerber [3] definition, and it has developed a Serenity Scale [6] that measure various factors of serenity including acceptance, inner haven, trust, belonging, perspective, contentment, present centered, benevolence and cognitive restructuring/self responsibility.

In relation to chronically illness, the acceptance of the new life situation caused by the disease has been shown to be important because it helps the patient to act in order to find oneself and the ability to find hope and confidence for the future [7]. It has also been shown in several studies that the ability to act in order to manage the situation caused by both disease and ageing is associated with the sense of self-esteem [8]-[10]. The higher the sense of self-esteem is, the grater is the ability to manage the situation [8]. The term self-esteem refers to the values the individual has of themselves that are often based on attitudes in the surrounding community [11]. Roberts and Messenger [12], on the other hand, argue that chronically ill older patients leave behind physical and material things while focusing on their inner self. The reason is that life events contribute to different priorities.

Serenity is seen as an outcome of the experience of the self [13]. The self can be developed in different levels and hence serenity. The personal self is the first and initial level including the safe self, level 1 of serenity, followed by the wise self, level 2 of serenity. The next level is the extended self, including the beneficent self, level 3 of serenity and finally the universal self, level 4 of serenity. The different levels build on each other and are thus hierarchical.

One problem with the concept of serenity for chronically ill older patients and patients in care at the end of life is that there is inappropriate emphasis placed on the patient's disease [5]. This can lead to increased anxiety, sadness or sense of isolation for the patient. The reason for this is that attention is put on a situation that cannot be changed, something that the patient will be constantly reminded of. On those occasions one important task for the registered nurse (RN) is to choose interventions whose purpose is to improve the sense of serenity [5].

There are several identified interventions that may improve the ability of older people to experience serenity [12]. The interventions are grouped under the categories: relationships, inner haven, cognitive restructuring and physical wellbeing, but Roberts and Messenger [12] point out the need of nursing knowledge to help the older patient find serenity. In order to develop the care of chronically ill older patients, it is necessary to clarify how the concept of serenity is used in relation to the patients. The purpose of the concept analysis is to clarify how the concept of serenity is used in nursing and in relation to the care of chronically ill older patients.

\section{Analysis}

The analysis follows Rodgers and Knafl ([2]: Chapter 6) evolutionary method of concept analysis. Concepts are not static terms but terms which change depending on how they are contextually used [14]. A concept is constantly changing. In "the cycle of concept development" it is described three events that must be met for a concept to be developed; its importance, use and application [14]. The significance is characterized by the concept's ability to describe a situation or phenomena. The use can occur in different verbal terms, but non-verbal too and the application refers to the situations in which a concept is used. To find out how a concept is developed one must take a systematic approach. The structure in a systematic approach is described in three phases; the initial phase, the core analysis phase and the further analysis phase [15]. Each phase includes different actions [15] [16] (Table 1).

\subsection{The Initial Phase}

\subsubsection{Choice of Concept and Context}

The choice of the concept of serenity was based on the fact that it is a recurrent theme in nursing. Through 
knowledge of its application, one can also reveal its strengths and limitations and with this knowledge, develop it ([2]: Chapter 6). The context refers to the discipline or literature to be included since each discipline uses and expresses a concept in an individual way. A context can also include how the concept is used within a discipline dependent on social group, tradition or culture ([2]: Chapter 6). To reach a specific area within nursing the concept of serenity was limited to chronically ill elderly care.

\subsubsection{Collection of Material and Choice of Texts}

In accordance with Rodgers and Knafl ([2]: Chapter 6), searches can be made both in the subject area and in related areas. In this way one obtains a broader search and includes related disciplines. To obtain an overview of the related areas that could be relevant in relation to nursing and elderly care, there was initially a search carried out on scientific databases and then divided into subject fields. Three subject fields were considered relevant, health sciences, health and medicine, and psychology. All the scientific databases mentioned under each subject field were searched. In each scientific database searches were conducted by the keywords, serenity AND nursing, and serenity AND caring. The keywords were combined with the limits of 65 years and older, aged, elderly or geriatric nursing, depending on what the scientific databases allowed. No restriction on the period of time the article was written was made.

Articles were sampled in three steps; by title, abstract and if the concept of serenity was present in the part of the article's results.

\subsection{The Core Analysis Phase}

Selection of articles and analysis process occurred initially simultaneously, since by reading the article's title and abstract it could be identified how the concept of serenity was related to surrogate terms, relevant uses, attributes, antecedents or consequences [14].

Article titles that were in some way related to the concept of serenity were sampled to step number two, reading the abstract. Abstracts related to the concept of serenity were selected to step number three, if the concept of serenity was present in the part of the result. Articles that had serenity in the result were read through several times in their entirety in order to become familiar with the content. Finally an analytical dialog with the material was performed in order to verify the relevance of the concept in relation to surrogate terms, antecedents, attributes, and consequences [14] [15] (Table 2). Besides how the concept of serenity was used, each article was analyzed based on its reference, aim, method, sample and result.

Table 1. Systematic approach described in three phases with their respective actions.

\begin{tabular}{cl}
\hline The initial phase & $\begin{array}{l}\text { Choice of concept } \\
\text { The context of a concept } \\
\text { Collection of material for concept analysis } \\
\text { The choice of texts } \\
\text { The core analysis phase }\end{array}$ \\
& $\begin{array}{l}\text { Surrogate terms } \\
\text { Antecedents } \\
\text { Attributes } \\
\text { The further analysis phase }\end{array}$ \\
\hline
\end{tabular}

Table 2. Questions asked to the material during the different phases of the analysis.
$\begin{array}{cl}\text { Surrogate terms } & \text { Do other words say the same thing as the chosen concept? } \\ \text { Antecedents } & \begin{array}{l}\text { Which events or phenomena have been associated with the concept } \\ \text { in the past? }\end{array} \\ \text { Attributes } & \text { What are the concepts characteristics? } \\ \text { Consequences } & \text { What happens after or as a result of the concept? }\end{array}$

(Tofthagen \& Fagerstrøm, 2010). 


\section{Results}

In this sample, the concept of serenity was used across various issues in nursing treated mental health, physical health, spirituality, experience of pain, self-care and palliative care. The concept was not only used in relation to the patient, but also in relation to his or her relatives.

A total of 49 scientific databases were found under the three subject fields, health sciences (21), health and medicine (19) and psychology (9). Of the 49 scientific databases, 5 occurred under different subject fields and 34 were not relevant to the study question. In the remaining 10 different scientific databases 504 citations were obtained, whereof 83 occurred in different scientific databases. Of the remaining 421 citations, 297 were not relevant. Finally 124 abstracts were read of which 19 articles $(n=19)$ made use of the concept of serenity in their results, and thus became the definitive sample. Articles derived from USA (8), Canada (1), Italy (2), Philippines (1), Taiwan (1), China (1), Denmark (1), Norway (1) and Sweden (3) (Figure 1).

\subsection{Surrogate Terms}

Surrogate terms to the concept of serenity were tranquility [17]-[19], peacefulness [20] [21], calm [22], contentment [23], or harmony [24]. The concept of serenity was also described with a combination of terms, or a part of a sentence such as; a quiet satisfaction with a sense of freedom [23], accepting your situation [25], to possess a sense of peace [24], an emotional experience of inner peace [26] or a psychological wellbeing [18] or a physical, mental and spiritual healing [27]. Söderhamn [28] describes serenity as faith in oneself, something that is needed for managing one's own care. Vellone et al. [18] [19] explain that serenity was used to describe the meaning of the quality of life. Quality of life was something experienced by caregivers of people with Alzheimer's before they were caregivers and placed under stress.

\subsection{Antecedents}

Events or phenomena that have taken place before serenity occurs are described as well as physical, emotional or spiritual processes or conditions. Whether it is described as a process or as a condition, it seems to be a situation from which the individual wants to be released. When the individual is released one can perceive serenity. Different kinds of processes that are mentioned are ageing [21] [29], dying [20] [22] [24] [30] and decision making [27] [31].

Ageing is described as a painful process beyond human knowledge as well as physical, emotional or spiritual dimensions, which one has to come through [21] [29]. The process is completed when ageing is accepted and only then can serenity be experienced. Dying is related to the insight that life is coming to an end and the emotional and spiritual pain that arises when one must leave loved ones and life [20] [22] [24]. The pain disappears with the acceptance of death [24]. Decision making is described as the agony you are exposed to before decisions are taken. The decision of leaving home and moving into a nursing home [31] or the step from a life of addiction to early sobriety [27].

Conditions preceding serenity occurring are the fear of death [30] or the physical suffering before death [17]. Another kind of condition is the emotional suffering in relation to mental illness [32] or physical, psychological and emotional stress [18] [19] [26] [33]. Stress is caused by the burden and the lack of freedom that disease, treatment and care demand [26] [33]. The condition is overcome by various coping strategies and then serenity can [26] [28] [32]-[34].

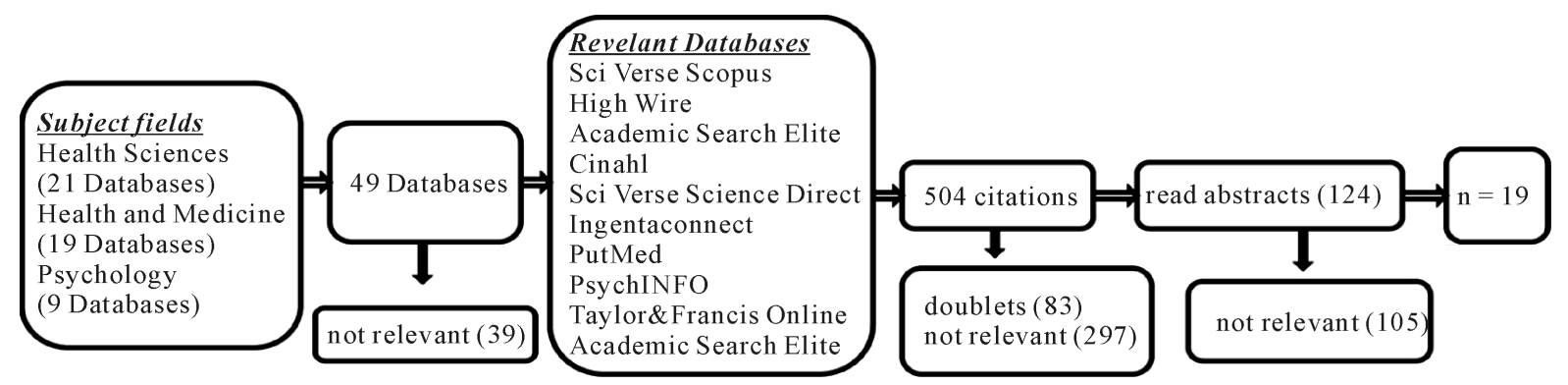

Figure 1. Overview over the study selection process. 


\subsection{Attributes}

The characteristics of the concept are described as different forms of emotional states, but also as active actions. The different forms of emotional states are confidence [35] and loving presence [22]. Blomqvist and Edberg [35] describe how older people, despite their persistent pain, lived with confidence in their situation, because of significant others who contributed to a safer environment, and thus it was easier to manage the pain. The loving presence is described like being here and now, despite severe disease [22].

The active actions are defined as coping strategies as part of serenity [28] [32]-[34]. De Guzman et al. [33] describe different forms of coping strategies that geriatric hemodialysis patients use to manage their situation. Another coping strategy characterizing serenity is a conscious agreement over a situation that cannot be changed, such as living in an institution [32]. Söderhamn [28] and Sørensen et al. [34] believe that coping strategies are fundamental in the self-care which characterizes serenity. Another active action was acceptance [21] [25] [27] [29]. The acceptance was done by only accepting, as in relation to ageing [21] [29], accepting by mental processing of a situation [25] or accepting a new way of life after addiction, which was made after re-evaluating their life [27].

\subsection{Consequences}

Consequences or the result of serenity is described as experiencing the self [20] [24] [25] [29] [35], an inner strength [22] [33], reverence [26], stillness [21] [31] [32], freedom [18] [19] or the feeling of being healed [27]. All references express an experience of a higher state beyond the physical. The higher state is achieved in connection to a situation which is overcome. Regardless if the situation is described as a process [20]-[22] [24] [27] [29] [31] or a condition [17]-[19] [26] [28] [30] [32]-[34] it is overcome by having accepted it [21] [27] [29] or having dealt with it [28] [32] [33]. Dealing is seen as a self-care action that the patient manages to overcome the situation themselves or with the help of the nurse [28] [32].

The self may be the sense of the self [29] [35], the dignity and the acceptance of the self [25], the empowering of the self [20] or the self-worth [24].

\subsection{The Further Analysis Phase}

Based on data underlying this study, it was possible to put forward a clarification of the concept of serenity and how it is used in nursing and in relation to the care of older patients. By linking the concept surrogate terms, antecedents, attributes and consequences the following definition is revealed:

Serenity is a state of physical, mental, emotional and spiritual balance that presents itself when an undesirable condition in life can be managed or accepted. Experiencing serenity is a requirement for the older patient to be able to find or develop the self and continue with dignity (Figure 2).

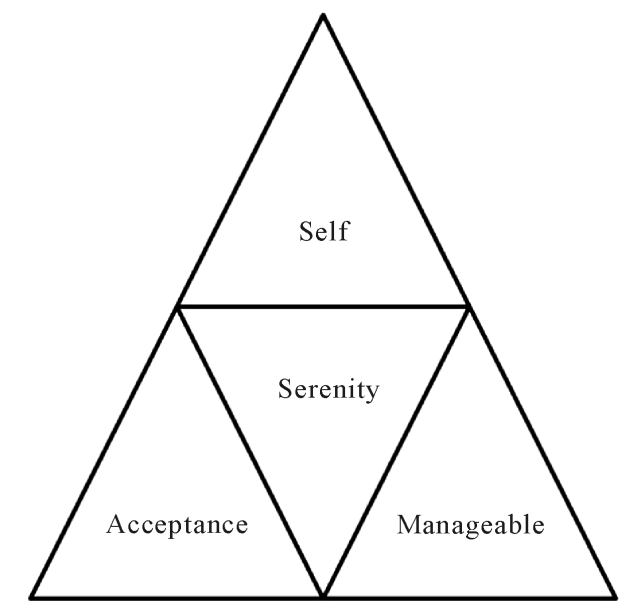

Figure 2. Schematic figure over further analysis phase. Serenity is achieved when undesirable conditions in life can be managed or accepted. Serenity is a requirement in order to be able for developing the self. 


\section{Discussion}

The result will be discussed based on the further analysis phase and its connection to the self [13].

The conceptualization that resulted in this analysis shows that serenity is described as a state of balance required in order to experience self [13]. The state of balance is preceded by undesirable life conditions that you can leave behind either by managing them or by accepting them. Roberts and Whall [13] argue that self can be experienced on four different levels of serenity. On level one (the lowest level of serenity) this represents the personal self and evolves strategies to achieve a perception of safety, one finds problem-solving. De Guzman et $a l$. [33] use the word manage and argue that geriatric hemodialysis patients use different forms of coping strategies in order to manage their situation. Another way to manage a situation was through self-care actions [28] [34]. In a study conducted by Hurd Clarke and Bennett [36] it was revealed that self-care actions in a group of older people with multiple chronic conditions was considered necessary because this offered a greater degree of independence. Self-care was also something one made use of when the physician could not offer any more. One self-care strategy that was mentioned was pain control, which coincided with one of the interventions suggested by Roberts and Messenger [12] under the category physical wellbeing. However, it doesn't become clear how the pain control can be performed. Blomqvist and Edberg [35] suggest that significant others are important in relation to pain control since they help to increase the sense of safety. Roberts and Messenger [12] talk about relationships and suggest different interventions to assist the older person in order to increase opportunities for relationships, both physical and on a higher level. However, nothing is mentioned about whether relationships would help in pain control.

Level two of serenity, the wise self, is characterized in obtaining perspective of the situation [13]. Here one can find acceptance. The acceptance of a situation was seen as a part of serenity [21] [25] [27] [29]. Acceptance was an active action that was defined as a coping strategy [28] [32]-[34]. A coping strategy is defined by Lazarus and Folkman ([37]: p. 141) as efforts in order to handle an event in life considered to exceed our ability. To be able to cope requires an insight or recognition about the situation. This is seen as a process where the individual can shift strategies [37]. Maybe for this reason acceptance is described in different ways such as only accepting [21] [29], mental processing [25] or after re-evaluating their life [27]. Roberts and Messenger [12] suggest, under the category cognitive restructuring, interventions in order to identify what can and cannot be changed in situations. It would be of interest to examine to what extent this can lead to higher coping strategies for the older person.

In this analysis it is revealed that the significance, uses and application of serenity in relation to older chronically ill people are in accordance with the two lowest levels of intensity of serenity included in the personal self described by Roberts and Whall [13]. In a recently study conducted by Brobeck, Odencrants, Bergh and Hildingh [38] revealed like Roberts and Fitzgerald [5] that RNs put so much focus on patient's diseases that they forget to make sure all needs [5] [38]. It is tempting to conclude that reason why serenity only occurs on the two lowest levels of serenity is because focus largely is on physical needs. It may also be that the diversity of surrogate terms and sentences that are close to the concept of serenity in meaning are used interchangeably and therefore there is a lack of clarity. This also affects the concept's significance, but the various authors' consensus of the concepts consequences as experiencing the self [20] [24] [25] [29] [35] suggests that the concept has a great importance in relation to older chronically ill patients in order to obtain the ability to continue daily life and have the ability to develop the self.

\section{Limitations}

Rodgers and Knafl ([2]: Chapter 6) method of concept analysis proved to be an appropriate method to clarify how the concept of serenity is used in nursing and in relation to the care of older patients. Since the method requires an analysis from different perspectives such as; surrogate terms, antecedents, attributes and consequences one obtains a comprehensive view over the studied concept. Although the method itself provides opportunities to clarify a concept some parts of the proceedings in this study must be noted.

Despite the fact that the literature search was extensive and involved different disciplines, this did not result in a large number of articles. Despite a large number of hits on the concept of serenity, the number of articles was reduced by reason of the limitation of elderly care. It would be desirable with a larger number of articles in the result, but whether it would influence the outcome of the result is difficult to say.

One difficulty that arose at an early stage in the analysis process was whether data could be grouped in a 
different way. Rodgers [16] highlights the importance of asking oneself that question in order to reduce the risk of bias. It turned out that in some cases it was difficult to distinguish between the attribute and the consequences of the concept, such as loving presence, when many of the words are near each other in significance and different authors use the same word but in a different way from one another. The same difficulties existed in the analysis of surrogate terms, where words could be confused with an attribute, such as calm. This shows the need to clarify concepts in nursing and the importance of accuracy in the use of them.

To confirm respective terms under surrogate terms, antecedents, attributes and consequences, the core analysis phase was made twice and tested against data. By discussing the result with colleagues an opportunity was given to test if the material could be perceived in a different way. The only question that arose was whether and how serenity can be understood on the basis of a physical dimension.

\section{Conclusions}

The concept of serenity is used in relation to chronically ill older patients as a state of physical, mental, emotional and spiritual balance that presents itself when an undesirable condition in life can be managed or accepted. Through the experience of serenity, the older patient is able to find or develop the self in order to continue daily life. Managing the situation is seen as self-care action while accepting the situation is seen as a coping strategy.

Serenity can be experienced in four hierarchical levels where each level is associated with the ability to develop the self, from the personal self to the extended self. This analysis concludes that in relation to chronically ill older persons the concept is used in the two lowest described levels. More knowledge is needed about the factors that enable older patients to experience serenity, and how they work for the concept to be used on all levels of the self. More knowledge is also needed about whether registered nurses can support older patients in finding serenity with the help of nursing interventions.

\section{References}

[1] Meleis, A.I. (2007) Theoretical Nursing. Development and Progress. 4th Edition, Lippincott Williams Wilkins, Philadelphia.

[2] Rodgers, B.L. and Knafl, K.A. (2000) Concept Development in Nursing. Foundation, Techniques and Applications. 2nd Edition, Saunders, Philadelphia.

[3] Gerber, W. (1986) Serenity. Living with Equanimity, Zest, and Fulfillment by Applying the Wisdom of the World’s Greatest Thinkers. University Press of America, New York.

[4] Bailey, J. (1990) The Serenity Principle: Finding Inner Peace in Recovery. Harper \& Row, New York.

[5] Roberts, K.T. and Fitzgerald, L. (1991) Serenity: Caring with Perspective. Scholarly Inquiry for Nursing Practice: An International Journal, 5, 127- 142.

[6] Roberts, K.T. and Aspy, C.B. (1993) Development of the Serenity Scale. Journal of Nursing Measurement, 2, 145164.

[7] Delmar, C., Bøje, T., Dylmer, D., Forup, L., Jakobsen, C., Møller, M., Sønder, H. and Pedersen, B.D. (2005) Achieving Harmony with Oneself: Life with a Chronic Illness. Scandinavian Journal of Caring Sciences, 19, 204-212. http://dx.doi.org/10.1111/j.1471-6712.2005.00334.x

[8] McGarry, J. (2008) Defining Roles, Relationships, Boundaries and Participation between Elderly People and Nurses within the Home: An Ethnographic Study. Health and Social Care in the Community, 17, 83-91. http://dx.doi.org/10.1111/j.1365-2524.2008.00802.x

[9] Westerhof, G.J., Krauss Whitbourne, S. and Freeman, G.P. (2012) The Aging Self in a Cultural Context: The Relation of Conceptions of Aging to Identity Processes and Self-Esteem in the United States and the Netherlands. The Journals of Gerontology, Series B: Psychological Sciences and Social Sciences, 67, 52-60. http://dx.doi.org/10.1093/geronb/gbr075

[10] Holmberg, M., Valmari, G. and Lundgren, S.M. (2012) Patients’ Experiences of Homecare Nursing: Balancing the Duality between Obtaining Care and to Maintain Dignity and Self-Determination. Scandinavian Journal of Caring Sciences, 26, 705-712. http://dx.doi.org/10.1111/j.1471-6712.2012.00983.x

[11] King, K.A. (1997) Self-Concept and Self-Esteem: A Clarification of Terms. Journal of School Health, 67, 68-70. http://dx.doi.org/10.1111/j.1746-1561.1997.tb06303.x

[12] Roberts, K.T. and Messenger, T.C. (1993) Helping Older Adults Find Serenity. Are There Potential Nursing Interventions That May Help Older Adults Reach a Serene State? Geriatric Nursing, 14, 317-322. 
http://dx.doi.org/10.1016/S0197-4572(06)80059-5

[13] Roberts, K.T. and Whall, A. (1996) Serenity as a Goal for Nursing Practice. Journal of Nursing Scholarship, 4, 359364. http://dx.doi.org/10.1111/j.1547-5069.1996.tb00388.x

[14] Rodgers, B.L. (1989) Concepts, Analysis and the Development of Nursing Knowledge: The Evolutionary Cycle. Journal of Advanced Nursing, 14, 330-335. http://dx.doi.org/10.1111/j.1365-2648.1989.tb03420.x

[15] Tofthagen, R. and Fagerstrøm, L.M. (2010) Rodgers' Evolutionary Concept Analysis—A Valid Method for Developing Knowledge in Nursing Science. Scandinavian Journal of Caring Sciences, 24, 21-31. http://dx.doi.org/10.1111/j.1471-6712.2010.00845.x

[16] Rodgers, B.L. (1991) Using Concept Analysis to Enhance Clinical Practice and Research. Dimensions of Critical Care Nursing, 1, 28-34. http://dx.doi.org/10.1097/00003465-199101000-00006

[17] Di Mola, G. and Crisci, M.T. (2001) Attitudes towards Death and Dying in a Representative Sample of the Italian Population. Palliative Medicine, 15, 372-378. http://dx.doi.org/10.1191/026921601680419410

[18] Vellone, E., Piras, G., Talucci, C. and Cohen, M.Z. (2007) Quality of Life for Caregivers of People with Alzheimer's Disease. Journal of Advanced Nursing, 61, 222-231. http://dx.doi.org/10.1111/j.1365-2648.2007.04494.X

[19] Vellone, E., Piras, G., Veturini, G., Alvaro, R. and Cohen, M.Z. (2012) Quality of Life for Caregivers of Persons with Alzheimer's Disease Living in Sardinia, Italy. Journal of Transcultural Nursing, 23, 46-55. http://dx.doi.org/10.1177/1043659611414199

[20] Kruse, B.G., Ruder, S. and Martin, L. (2007) Spirituality and Coping at the End of Life. Journal of Hospice and Palliative Nursing, 9, 296-304. http://dx.doi.org/10.1097/01.NJH.0000299317.52880.ca

[21] Santamäki Fischer, R., Norberg, A. and Lundman, B. (2007) I'm on My Way: The Meaning of Being Oldest Old, as Narrated by People Aged 95 and over. Journal of Religion, Spirituality \& Aging, 19, 3-19. http://dx.doi.org/10.1300/J496v19n02_02

[22] Kruse, B.G. (1999) The Lived Experience of Serenity: Using Parse’s Research Method. Nursing Science Quarterly, 12, 143-150. http://dx.doi.org/10.1177/08943189922106576

[23] Rizzo Parse, R. (2001) The Lived Experience of Contentment: A Study Using the Parse Research Method. Nursing Science Quarterly, 14, 330-338. http://dx.doi.org/10.1177/08943180122108481

[24] Mok, E., Wong, F. and Wong, D. (2010) The Meaning of Spiritual Care among the Hong Kong Chinese Terminally Ill. Journal of Advanced Nursing, 66, 360-370. http://dx.doi.org/10.1111/j.1365-2648.2009.05193.x

[25] Beadlesson-Baird, M. and Lara, L.L. (1988) Reminiscing: Nursing Actions for the Acutely Ill Geriatric Patient. Mental Health Nursing, 9, 83-94. http://dx.doi.org/10.3109/01612848809140911

[26] Chao, S.Y. and Roth, P. (2000) The Experiences of Taiwanese Women Caring for Parents in Law. Journal of Advanced Nursing, 31, 631-638. http://dx.doi.org/10.1046/j.1365-2648.2000.01319.x

[27] Rushing, A.M. (2008) The Unitary Life Pattern of Persons Experiencing Serenity in Recovery from Alcohol and Drug Addiction. Advances in Nursing Sciences, 31, 198-210. http://dx.doi.org/10.1097/01.ANS.0000334284.73730.75

[28] Söderhamn, O. (2013) Phenomenological Perspectives on Self-Care in Aging. Clinical Interventions in Aging, 8, 605608. http://dx.doi.org/10.2147/CIA.S45902

[29] Futrell, M., Wondolowski, C. and Mitchell, G.J. (1993) Aging in the Oldest Old Living in Scotland: A Phenomenological Study. Nursing Science Quarterly, 6, 189-194. http://dx.doi.org/10.1177/089431849300600407

[30] Hughes, T. and Jacobs-Lawson, J.M. (2008) Confronting Death: Perceptions of a Good Death in Adults with Lung Cancer. American Journal of Hospice \& Palliative Medicine, 25, 39-44. http://dx.doi.org/10.1177/1049909107307377

[31] Pilkington, F.B. (2005) Grieving a Loss: The Lived Experience for Elders Residing in an Institution. Nursing Science Quarterly, 18, 233-242. http://dx.doi.org/10.1177/0894318405277525

[32] Pickens, J.M. (1999) Living with Serious Mental Illness: The Desire for Normalcy. Nursing Science Quarterly, 12, 233-239. http://dx.doi.org/10.1177/08943189922107007

[33] de Guzman, A.B., Chy, M.A., Concepcion, A.F., Conferido, A.J. and Coretico, K.I. (2009) The Language of Coping: Understanding Filipino Geriatric Patients’ Hemodialysis Lived Experiences. Educational Gerontology, 35, 769-783. http://dx.doi.org/10.1080/03601270802708384

[34] Sørensen, L.V., Waldorff, F.B. and Waldemar, G. (2008) Early Counseling and Support for Patients with Mild Alzheimer's Disease and Their Caregivers: A Qualitative Study on Outcome. Aging \& Mental Health, 12, 444-450. http://dx.doi.org/10.1080/13607860802224342

[35] Blomqvist, K. and Edberg, A.K. (2002) Living with Persistent Pain: Experiences of Older People Receiving Home Care. Journal of Advanced Nursing, 40, 297-306. http://dx.doi.org/10.1046/j.1365-2648.2002.02371.x 
[36] Hurd Clarke, L. and Bennett, E.V. (2013) Constructing the Moral Body: Self-Care among Older Adults with Multiple Chronic Conditions. Health, 17, 211-228.

[37] Lazarus, R. and Folkman, S. (1984) Stress, Appraisal and Coping. Springer Publishing Company, New York.

[38] Brobeck, E., Odencrants, S., Bergh, H. and Hildingh, C. (2013) Health Promotion Practice and Its Implementation in Swedish Health Care. International Nursing Review, 60, 374-380. http://dx.doi.org/10.1111/inr.12041 
Scientific Research Publishing (SCIRP) is one of the largest Open Access journal publishers. It is currently publishing more than 200 open access, online, peer-reviewed journals covering a wide range of academic disciplines. SCIRP serves the worldwide academic communities and contributes to the progress and application of science with its publication.

Other selected journals from SCIRP are listed as below. Submit your manuscript to us via either submit@scirp.org or Online Submission Portal.
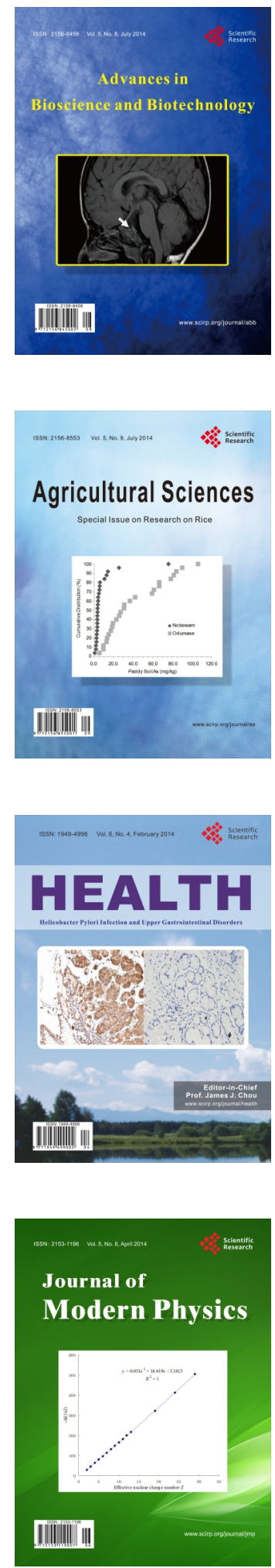
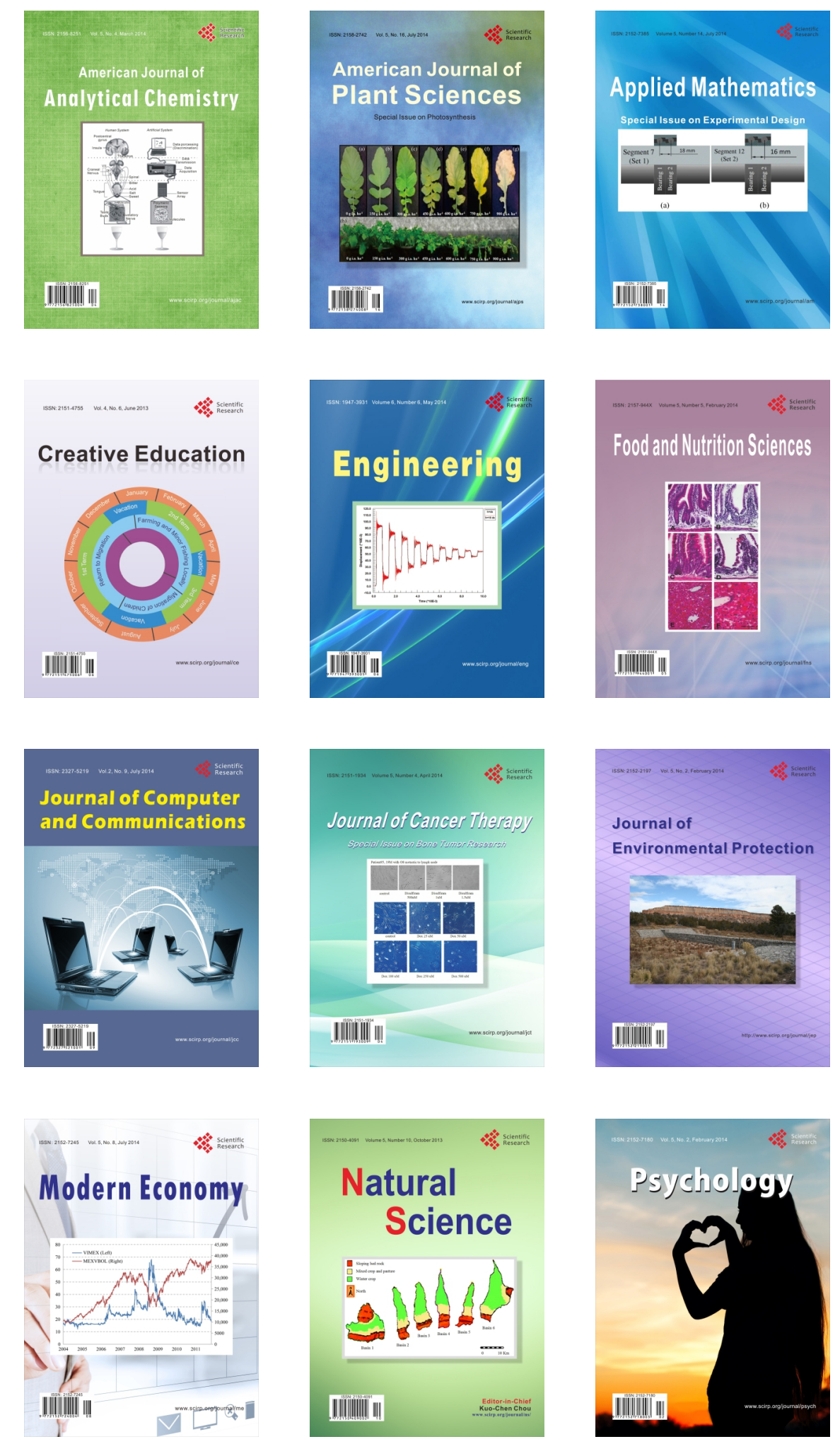